\title{
Electronic publishing, the end user, and medical education
}

\author{
Shane Godbolt
}

Traditionally, members of the medical profession have been well motivated users of medical publications. To practise excellence in health care or to do good research depends on being able to use in an effective manner the information base on which current knowledge is founded. Equally, career advancement depends not only on progressing through higher examinations but also on developing and adding to the knowledge base by research and writing.

Medical publications and their development Fundamental to the acquisition of information searching and handling skills is an understanding of the infrastructure on which knowledge is based (primary sources) and the substructure through which it can be accessed and used (secondary sources) (table). These concepts require insight into the role of medical journals, which has been well described by Lock, ${ }^{1}$ and practical experience of searching for information.

Medicine is fortunate in its great bibliographical tool Index Medicus, which has done so much to facilitate the progress of medical science by organising an effective means for retrieval and dissemination of journal reports throughout the medical community world wide. The MeSH thesaurus is unparalleled in the depth and thoroughness of its indexing, besides which the effectiveness of text word retrieval may often be immeasurably weaker.

Today's user of medical information services has to cope with the continuing information explosion, the scatter of reports, and declining library budgets, all of which lessen the likelihood of access on the spot to required materials.

\section{Technological change}

The world is changing faster than even we, who in medical libraries are at the forefront of implementing new techniques in information provision, ever dreamed possible. Familiar and essential services to users can now be provided

Library, Charing Cross and Westminster Medical School, St Dunstan's Road, London W6 8RP S Godbolt

\begin{tabular}{ll}
\hline Primary sources & Secondary sources \\
\hline Original research journals & $\begin{array}{l}\text { Indexing and abstracting } \\
\text { journals }\end{array}$ \\
Theses & Review journals \\
Research reports & Books \\
Personal communications & Guides to publications \\
\hline
\end{tabular}

in radically different exciting ways using the new and powerful tools that the computing and telecommunication technologies have afforded us. The process is one of tension and turbulence but it is generating excitement and enthusiasm. Technology is bringing benefits and accelerating the pace of change. A new infrastructure is emerging and, more importantly, people eager and able to use it.

\section{Focus on the end user}

Discussing the future of the intellectual infrastructure of the United Kingdom, Professor Stonier of Bradford University stated 'The impact of computers and related information/ communication technology is parallel to that of the printing press but much more profound. Unlike computers, the printing press never got into the home. In contrast, the computer is invading every facet of industrial, business, and personal life'.

The development of the end-user market has been dramatically fuelled by developments in computer hardware and software and of storage techniques. As prices of microcomputers have fallen, specifications have improved and small powerful personal computers, including personal lap-tops, are commonplace, particularly among medical personnel, whose exposure to technology is likely to be higher than average. Medicine has been fortunate in having the world's first computerised database, derived as a byproduct of the compilation of Index Medicus at the National Library of Medicine in the United States. Called MEDLARS (Medical Literature Analysis and Retrieval System), this started in 1963 and the online files, which were developed throughout the '70s, are known as MEDLINE (MEDLARS onLINE). For over a decade now use of online bibliographical databases, with MEDLINE predominating, has been well established among United Kingdom health care librarians. A new trend has been interest from some end users in doing their own searching. An innovative 'MEDLINE for medics' course was run at St George's Hospital Medical School in 1989 for health care professionals, ${ }^{3}$ and end-user searching of online services is already well established in the United States, where electronic infrastructures are much more highly developed than they are in the United Kingdom. Many of the larger American medical libraries provide subsets of journals (comprising 150-500 titles over three 
years) through terminals available in the library or over a local area network so that users are able to search free of charge the contents of the journal holdings of their own library. Having built up knowledge and expertise in database searching, these users have been targeted with success by commercial services such as BRS Colleague's Afterdark. ${ }^{4}$ Such services with specially designed software to overcome the unfriendly computer interface of large online systems have generally not been available in the United Kingdom nor has it really been cost effective for United Kingdom users to search MEDLINE directly. Only the skilled intermediary understanding the structure of the database and familiar with the $\mathrm{MeSH}$ thesaurus could use the system quickly and effectively, retrieving references at a reasonable cost. Even the facility of abstracts was usually not exploited because the costs of downloading or printing abstracts in any great quantity from online hosts were too high.

\section{Computer networks-Joint Academic Network (JANET)}

The end user has again benefited as communication networks for computers have become more sophisticated. The provision of JANET, a free private network which was established in 1984, has provided further incentives for the British academic medical community to exploit. The network currently links well over 40000 users to the facilities of over 1700 registered computers on more than 150 higher education sites. Its purpose is to facilitate access to academic computing resources across the United Kingdom in the interests of teaching and research. Computer users can be linked on a local campus, across other sites, and to the national and international academic community with links to the Packet Switching System, the International Packet Switching System and a variety of American networks. 'Invisible colleges' can communicate quickly and freely through electronic mail, and all standard services for collaboration and communication are provided.

Computerised catalogues have for some years now been well established in libraries. Many library catalogues have been made available locally and nationally on JANET. Card catalogues have been replaced by terminals known as OPACS (Online Public Access Catalogues), which offer a range of flexible and powerful searching options (according to the particular software program chosen) through which material may be sought by users. Over 50 library databases, to which users may have access from their own terminals, are now available on JANET. In their own institutions users can carry out searching, reviewing, and reservation operations without needing to visit the library. Individual libraries, however, are likely to wish to manage borrowing, other than by their own users, as an interlibrary loan operation. This is a good example of where technology can overcome boundaries, but practical difficulties are still restrictive.

Congestion is sometimes a problem using
JANET, and there have been reports of virus infection following the downloading of public domain software to personal computers. As yet unresolved is the whole question of NHS access. Like all successful innovation JANET has experienced growing pains, but its continued development is vital and assured. SuperJANET, based on fibre optics, is already on the horizon. ${ }^{6}$

\section{Compact disc technology}

The most significant of all the elements that are currently influencing the pattern of radical change is the advent of optical disc and its introduction into libraries. CD-ROM (Compact Disc Read Only Memory) has emerged as the new medium for the storage and retrieval of large volumes of data by end users. It has attracted much interest in medical reports, ${ }^{7-9}$ as well as in publications of the computing and library world.

A single disc, identical in appearance and size to a music compact disc, holds 500 million characters or 200 books of 300 pages each. Such an advance has not always been straightforward and there have been teething problems, such as compatibility, to overcome as the systems are so new. What is exciting is that these new electronic products are influencing profoundly the mechanisms by which journal reports are accessed, retrieved, and used. These menu driven systems, introduced into the United Kindom in 1987 and, which it must be remembered are designed for end users not librarians, have in a very short time become even more sophisticated, user friendly, and powerful. Dr Robert Hogan, a doctor who serves as software adviser to the Fournal of the American Medical Association has rightly described the technology as 'a quantum leap' ${ }^{7}$ There are no difficult command languages to master, no telecommunications costs, and the microcomputer is readily accessible. The system has become 'in-house'. There are now over $80 \mathrm{CD}$-ROMs aimed at the medical and health market listed in a 1991 directory of compact disc products. ${ }^{10}$ Many of these are based on MEDLINE, which is itself available from several vendors. A checklist for evaluating the CD-ROM versions of the MEDLINE database has been compiled by Hewison. ${ }^{11}$

It is not an overstatement to say that users, particularly in the medical and academic sector, are ecstatic at the power of the information retrieval to which they have direct access. Information provision has been transformed as research support to existing user groups has been enhanced and new user groups, drawn particularly from among paramedical staff and students, have been attracted.

A key factor in the popularity of CD-ROM has been that after more than a decade, when database searching has remained largely the province of the skilled intermediary, control is now passing back to users. Users perceive the following advantages:

- Ability to search for themselves

- To search at their convenience without time constraints

- Facility to view abstracts 
- Repeated access to publications

- For MEDLINE MeSH or text word (from the title or abstract) approach

- Facility to store and update searches

- Facility to download-that is, capture information from the system onto the user's own disc for later use on their own personal computer to manage the references selected for quick retrieval and bibliography generation when writing.

This is a major and crucially important development.

Paramedical staff and medical students, who have traditionally been barred because of costs from using online facilities, can make use of this technology on the same terms as other users. New products are leading to increased use of published reports as well as to more comprehensive, effective, and relevant information services and teaching programmes. ${ }^{8}$ As the medical student curriculum changes emphasis and the move to student centred learning gains momentum the value of CD-ROM is enhanced further. British experience reflects that of McMaster University where CD-ROM MEDLINE has proved a boon for undergraduate medical students. To quote the head of systems and technical services at McMaster Library, 'MEDLINE is probably the first significant database that students are going to encounter. It has become an integral part of the whole educational programme'. The provision of English abstracts for many of the European and Japanese foreign language titles is opening up these areas of medical publications in a timely fashion. Before CD-ROM, access to English abstracts of foreign language material was normally prohibitively expensive.

Developments have been rapid and fiercely competitive. All United Kingdom medical school libraries now have MEDLINE and other databases, as do many smaller NHS libraries. An innovative scheme has been described in the North West Thames Region, in which CDROM technology has been established within a few months in nearly all the NHS medical libraries in the region. ${ }^{12}$

\section{The Products \\ MEDLINE}

The market leader is not surprisingly MEDLINE, which because of its price is the database of first resort. Untypically, software is available from a number of vendors. Compact Cambridge MEDLINE from Cambridge Scientific Abstracts was the first to arrive from the United States in 1987 and together with SilverPlatter MEDLINE has an established user base. CDPLUS is a relatively recent arrival with some new and important features, notably the ability to search five years' references simultaneously using two CD-ROM discs. Until the arrival of CD-PLUS last year one year per disc had been the norm for the MEDLINE product. The CDPLUS product, which has been reviewed by Whitsed, ${ }^{13}$ also includes a useful 'mapping' facility which allows the user to enter a term which will then be matched automatically against the Index Medicus thesaurus MeSH. All leading vendors now update MEDLINE monthly and offer the facility familiar to online searchers of 'exploding' $\mathrm{MeSH}-\mathrm{a}$ mechanism by which one general and several more specific terms can all be searched without the need to enter each term separately-for example, arm injuries: forearm injuries, radius fractures, ulna fractures.

Other CD-ROM databases which have quickly found a market niche are Cumulated Index to Nursing and Allied Health Literature (CINAHL), CANCER-CD, and Science Citation Index.

A slightly different and interesting approach is Compact Library AIDS, which includes references from MEDLINE, a major AIDS textbook, and the full text of several journals concerned with AIDS. ${ }^{14}$

Other interesting products on the market are compact disc versions of the Oxford Textbook of Medicine, Consult (Scientific American Medicine), and Martindale.

DISKETTE PRODUCTS FOR CURRENT AWARENESS A number of new products have been produced and priced for end users or departments. Examples are the familiar Current Contents series and two new products Reference Update and Medical Science Weekly. Both Current Contents and Medical Science Weekly plan to include abstracts shortly. An American review concluded that Current Contents and Reference Update provided not only an excellent mechanism for keeping abreast of biomedical publications, with a personal computer but also both offered an attractive alternative to manual or online searching. ${ }^{15}$ Product reviews of Reference Update and Current Contents ${ }^{16}$ and Medical Science Weekly ${ }^{17}$ should encourage librarians and users to use electronic updating services, which seem to be cost effective.

\section{Personal reference management}

Downloading references from the new products for use in a personal database is becoming commonplace. A number of specialist products have been launched to assist the publishing doctor and scientist. Three specialised products dominate

- Pro-Cite

- Reference Manager

- $\mathrm{Bib} / \mathrm{Search}$

It is clearly very attractive to be able to take sets of downloaded records straight into a local database without the necessity for retyping. Most compact disc and diskette services offer compatibility with all the products mentioned above. Useful advice on evaluating personal reference management software has been compiled by Moore, ${ }^{18}$ and products available have been compared by Herman ${ }^{19}$ with specific reference to downloading from MEDLINE or CD-ROM.

Copyright restrictions are important but some issues remain to be solved. Advice is given by Norman. ${ }^{20}$ 
The future

End users are seen by the host and producer organisations as a large and relatively untapped market, and all future marketing initiatives are likely to be directed to them. New products are often appearing experimentally; witness the launching of the CHEST/ISI (Combined Higher Education Software Team/Institute of Scientific Information) initiative in February this year, through which any user connected to JANET, whose institution has signed the contract, may have access to the Science Citation Index and Current Contents online from Bath University. The full implications of projects like ADONIS, fuelled by the concern of publishers with revenue, remain to be seen. ${ }^{21}$ As users become more familiar with the technology and the products they are likely to become more discerning.

A Lancet editorial has discussed effective search strategy and warned that the apparent simplicity of the technology does not obviate all the traditional difficulties associated with searching for and retrieving information. ${ }^{22}$ How Europe will tackle its increasing dependence on American information systems, notably MEDLINE, is another challenge facing us. Some standard British and European journals are not on MEDLINE. ${ }^{23} 24$

Europe urgently needs access to databases like Excerpta Medica's EMBASE, which is being offered with significant academic discounts this year via the online service Data-Star in order to allow librarians and users affordable access. In the United Kingdom to have access to the Department of Health and Social Security's database on CD-ROM would be a major advance, but what about costs? What about document delivery? Users' expectations are increasing, but to trace 'grey publications' and deliver the actual document to the user may not be as easy as locating it on a database. There are problems to overcome. Users may, however, expect that future developments will be user focused. They will have a wider range of choices than ever before, transcending library walls and institutional boundaries. As local, national, and international networking infrastructures develop users may look forward to operating from personal workstations where they can access information, download, manipulate, and transfer it as well as communicating with colleagues.

As these profound changes take place libraries will be judged on what they can provide access to, rather than their holdings, which will need to be core.

The foundations for the future are being laid now as CD-ROM databases, along with those mentioned on diskette, are effectively democratising access to powerful retrieval tools. The role of librarians and information professionals is changing as they seek to support users in exploiting the new resources.

Structured training programmes, support, and advice will need to be available and information handling skills courses are likely to become a part of the norm in undergraduate and postgraduate medical education. What none of us-librarians or users-should forget is that searching, which used to doom us all to poring over heavy tomes, minuscule print, and hours of tedium, is now bright, fun, and helpful. The technology will continue to develop and change, but as long as the fun stays who cares!

1 Lock S P. Medical journals. In: Walton J, Beeson P B, Scot $\mathrm{R} \mathrm{B}$, eds. The Oxford companion to medicine. Vol I. Oxford: Oxford University Press, 1986: 746-54.

2 Stonier T. The future of the intellectual infrastructure of the UK. In: Brindley L J, ed. The electronic campus: an information strategy. Proceedings of a conference held on 28-30 October 1988. London: British Library Board, 1989: 114-6. (Library information research report 73.)

3 Lyon E. MEDLINE-for-medics: an online searching course for health-care professionals. Health Libraries Review 1989; 6: $141-9$.

4 Janke R V. BRS/Afterdark: the birth of online self-service. Online 1983; 7: 12-29.

5 Buxton A. JANET and the librarian. The Electronic Library 1988; 6: 250-63.

6 JUGL' 90 conference report. $\mathcal{H}$ UGL Newsletter Winter 19909/91; No 2: 4-7.

7 Goldman B. CD-ROM technology: the answer to congestive shelf future? Can Med Assoc f 1989; 141: 816-7.

8 Pentelow G M. New technology in medical libraries: aiding literature searches and providing new services. $B M \mathcal{F} 1989$ 298: 907-8.

9 Kaltenborn K F. Literature data banks for university and medical research. A report of experiences with the use of the Medline database in a CD-ROM version. Med Klin 1989; 84: 339-43.

10 Mitchell J, ed. The CD-ROM directory 1991. 5th ed. London: TFPL Publishing, 1991 .

11 Hewison N S. Evaluating CD-ROM versions of the Medline database: a checklist. Bull Med Libr Assoc 1989; 77: 332-6.

12 Wentz R, Whitsed $N$. Getting together with compact disc: a regional MEDLINE CD-ROM initiative for libraries. Health Libraries Review 1990; 7: 2047.

13 Whitsed N. Product review: CD-PLUS MEDLINE. Health Libraries Review 1990; 7: 233-5.

14 Huth E J. Compact Library AIDS: medical literature moves toward its future. Ann Intern Med 1988; 109: 694.

15 Brahmi F A. Current Contents on diskette and Reference Update. MD Computing 1990; 7: 55-8.

16 Lyon E. Reference Update and Current Contents: a review. Health Libraries Review 1990; 7 : 37-9.

17 Whitsed N. Product review: Medical Science Weekly. Health Libraries Review 1990; 7: 171-2.

18 Moore C. Personal reference management software: how to evaluate it? Health Libraries Review (in press).

19 Herman D. Downloading from MEDLINE: a comparison of personal database software. Health Libraries Review (in press).

20 Norman J. CD-ROM and copyright. In: Moore C, Gunn $A$ A, eds. CD-ROM a practical guide for information professionals. London: UKOLUG and the British Library Board, 1990: 37-8.

21 Stern B T, Compier H C J. ADONIS-document delivery in the CD-ROM age. Interlending and Document Supply 1990; 18: 79-87.

22 Anonymous. Searching MEDLINE [Editorial]. Lancet 1988; ii: $663-4$.

23 Franklin J. Can European biomedical literature survive? The increasing dependence of European literature on American information systems. In: Armstrong C J, Hartley R J, eds. ONLINE information retrieval: today and tomorrow. Oxford: Learned Information, 1990.

24 Mayhew J. A case for local current-awareness publications. Health Libraries Review 1988; 5: 61-5. 